\title{
On The Sampling In Imaging Microwave Radiometers
}

\section{Skou, Niels}

Published in:

Digest - International Geoscience and Remote Sensing Symposium (IGARSS)

Publication date:

1988

Document Version

Publisher's PDF, also known as Version of record

Link back to DTU Orbit

Citation (APA):

Skou, N. (1988). On The Sampling In Imaging Microwave Radiometers. In Digest - International Geoscience and Remote Sensing Symposium (IGARSS) (Vol. 1, pp. 17-18). IEEE.

\section{General rights}

Copyright and moral rights for the publications made accessible in the public portal are retained by the authors and/or other copyright owners and it is a condition of accessing publications that users recognise and abide by the legal requirements associated with these rights.

- Users may download and print one copy of any publication from the public portal for the purpose of private study or research.

- You may not further distribute the material or use it for any profit-making activity or commercial gain

- You may freely distribute the URL identifying the publication in the public portal

If you believe that this document breaches copyright please contact us providing details, and we will remove access to the work immediately and investigate your claim 


\title{
ON THE SAMPLING IN IMAGING MICROWAVE RADIOMETERS
}

\author{
N Skou \\ Electromagnetics Institute, \\ Technical University of Denmark, \\ B 348, DK 2800 Lyngby, Denmark
}

\section{ABSTRACT}

In imaging radiometer systems the necessary sampling time is dependent on the dwell time per foot-print.

Traditionally two different approaches are seen: either a sampling time equal to the dwell time per foot-print, or sampling twice per dwell time. The correct sampling is between these two extremes: a sampling time of $70 \%$ of the dwell time per foot-print is required for realistic antenna patterns.

In an imaging radiometer system the antenna foot-print moves across the scene to be sensed, and the dwell time per foot-print is defined as the time it takes the antenna beam to move a distance of one foot-print. When the antenna beam scans a scene with a certain brightness temperature distribution, this results in a cer tain variation in the input signal to the associated radiometer, hence there are certain requirements to the sampling in that radiometer. Quite clearly the spectrum associated with these input variations to the radiometer heavily depends on the dwell time per foot-print: the faster the scan, the quicker the variations or to say it differently: the wider the spectrum. But, as it will be shown in the following, also the actual shape of the antenna pattern plays an important role.

In mathematical terms the sensing by the moving antenna of the scene corresponds to a convolution of the antenna pattern with the brightness temperature distribution of the scene. Hen $c e$, to find the transfer function $\mathrm{H}(\mathrm{f})$ associated with that process it is assumed that the antenna beam sweeps across a delta function in the scene distribution. Then $H(f)$ is simply found as the Fourier transform of the antenna pattern (transformed to the time domain by means of the scan velocity - or the dwell time per foot-print).

Figure 1 shows a host of idealized antenna patterns. The patterns have been normalized to have equal $3 \mathrm{~dB}$ width, and without loss of generality - this has been assumed to be $2 \mathrm{sec}$ (i.e. the foot-print dwell time is $2 \mathrm{sec}$ ). Curve $\mathrm{A}$ represents a sector shaped pattern - often used for overview considerations. $B$ is the main beam of $a \sin x / x$ pattern. It may seem odd to in- clude that, as it is a completely unreal pattern having negative sidelobes! (IMPORTANT: we are dealing with power patterns as the brightness temperature to enter the antenna is a power measure). The reason is purely academic and will emerge a little later. The two next curves represent far more realistic patterns namely a $(\sin x / x)^{2}$ having $-13 \mathrm{~dB}$ side lobes and ( $\sin$ $\mathrm{x} / \mathrm{x})^{4}$ with - $26 \mathrm{~dB}$ first side lobes. This statement is supported by an investigation of the normalized patterns of two actual antennas: one with a $140 \lambda$ aperture $(1.4 \mathrm{~m}$ at $30 \mathrm{GHz}$ f.ex.) and one with a $600 \lambda$ aperture $(2 \mathrm{~m}$ of $90 \mathrm{GHz}$ f.ex.). When plotted on Figure 1, (not done here as it tends to obscure the figure), the two curves lie nicely between curves $C$ and $D$. Finally curve $E$ is a Gaussian pattern - also sometimes used as a reference for overview considerations.

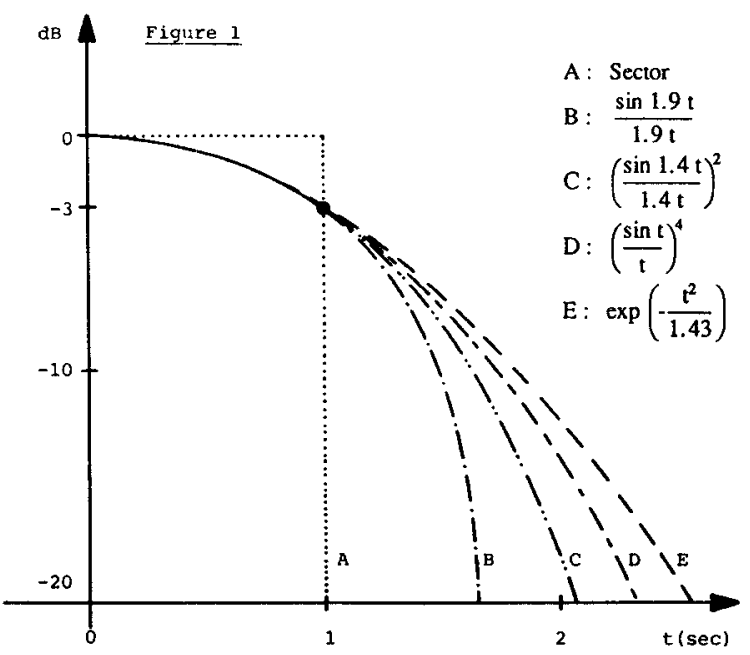

As already mentioned the transfer function of the scanning antenna is found by simply Fourier transforming these power patterns and the results are illustrated in Figure 2. The sector shaped pattern transforms into a $|\sin x / x|$ with zeros at $n \cdot 1 /(2$ $\mathrm{sec})=\mathrm{n} \cdot 0.5 \mathrm{~Hz}$. Likewise the $\sin \mathrm{x} / \mathrm{x}$ pattern transforms into a box shape having a total width of $1.9 / \pi=0.6 \mathrm{~Hz}$. The transform of the $(\sin x / x)^{2}$ pattern can be found by a convolution in the frequency domain of two box patterns and it is a triangle extending out to $\pm 1.4 \pi= \pm 0.45 \mathrm{~Hz}$. Again the transform of the $(\sin x / x)^{4}$ can be found by a convolution of two triangles - or by consulting tables of Fourier transforms. The result is: 
$H(f)=\left\{\begin{array}{c}\frac{3 \pi^{3}}{4} f^{3}-\frac{3 \pi^{2}}{2} f^{2}+1 \\ -\frac{\pi^{3}}{4} f^{3}+\frac{3 \pi^{2}}{2} f^{2}-3 \pi f+2 \\ 0\end{array}\right.$

$0 \leq f<\frac{1}{\pi}$
$\frac{1}{\pi} \leq f<\frac{2}{\pi}$
$\frac{2}{x} \leq f<\infty$

Finally the Gaussian pattern transforms into another Gaussian curve:

$$
H(f)=\sqrt{1.43 \cdot \pi} \exp \left(-1.43 \cdot \pi^{2} f^{2}\right)
$$

(note that the two last transforms (D and E) cannot be separated in the graphical representation of Figure 2.

Now the appropriate sampling of these spectra shall be discussed taking $-20 \mathrm{~dB}$ aliazing as criterion. Traditionally two different attitudes have been taken: either a sampling time equal to the dwell time per foot-print [Gloersen and Barath, 1977], ["The NIMBUS-7 Users Guide", 1978], or - by a "pseudo Nyquist argument" - sampling twics per dwell time [Hollinger and Lo, 1984].The first corresponds to $f_{s}=1 / 2 \mathrm{~Hz}$ in our case, the second to $\mathrm{f}_{8}=1 \mathrm{~Hz}$. As it will become clear in a moment the correct answer is between these figures.

If one makes overview considerations using the sector antenna (A) it is correct that appr. $1 \mathrm{~Hz}$ sampling is required. And even with this high rate some aliazing must be endured due to the large lobe around $0.7 \mathrm{~Hz}$, (some filtering could alleviate that problem).

The other extreme is found using the awkward antenna pattern (B): this is from a sampling point-of-view the ideal pattern having in the frequency domain a sharply limited, quite narrow form. A sampling frequency of $0.6 \mathrm{~Hz}$ is adequate and no aliazing is present.

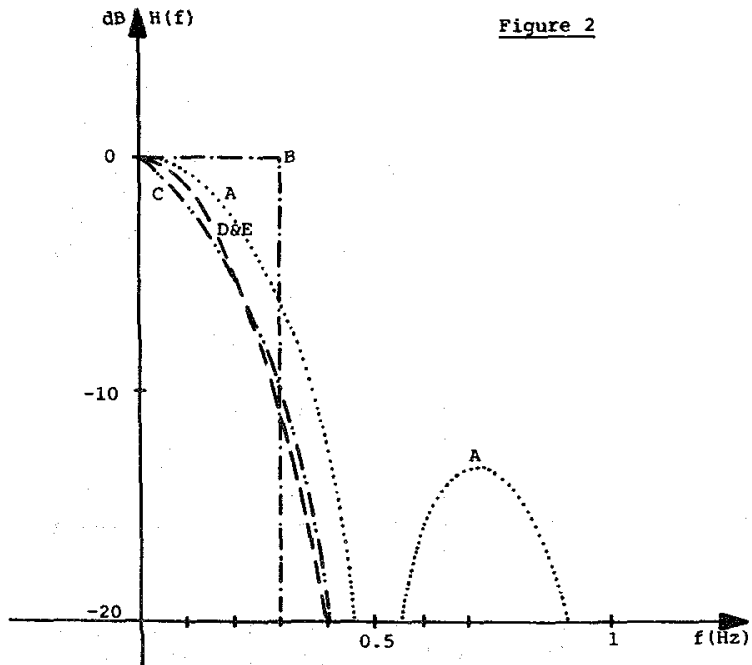

Tuming to the more realistic patterns $C, D$, and $E$ it is seen that a sampling frequency around $0.7-0.8 \mathrm{~Hz}$ is required depending on which amount of aliazing can be accepted. Note, that in no case is $0.5 \mathrm{~Hz}$, i.e. equal sampling time and dwell time, adequate.

The antenna transfer function is slightly modified by the radiometer itself through the low pass filtering corresponding to the integrator of the radiometer. This may be implemented as a digital integrate-and-dump circuitry resulting in equal integration time and sampling time. The transfer function of the radiometer is then of the $\sin x / x$ type with zeros at multiples of the sampling time.

Figure 3 displays the total situation $\mathrm{H}_{\mathrm{TOT}}$ for an antenna transfer function $\mathrm{H}_{\mathrm{A}}$ corresponding to the realistic patterns $\mathrm{D}$ and $\mathbf{E}$ (and approximately for $\mathbf{C}$ ), having selected a sampling frequency $\mathrm{f}_{\mathrm{s}}$ of $0.7 \mathrm{~Hz}$ and including the transfer function

$\mathrm{H}_{\mathrm{RAD}}$ of the radiometer. The transfer function of the radiometer slightly modifies the antenna response and the level of aliazing is very low: $\max -20 \mathrm{~dB}$ (and lower near to zero $\mathrm{Hz}$ ).

Hence, as a rule of thumb, in an imaging radiometer system with a 2 sec dwell time per foot-print a sampling time of $1 / 0.7 \mathrm{~Hz}$ $=1.4 \mathrm{sec}$ is required. $\mathrm{r}$ in general: a sampling time of 0.7 times the dwell time per foot-print is required.

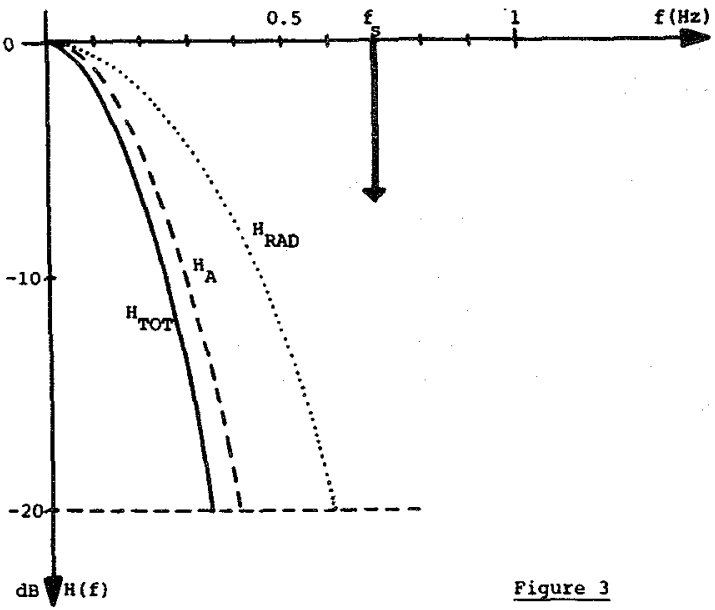

Finally it shall be stated that finding the upper limit of the sampling time is interesting in an attempt to keep the data rate from a given radiometer system as low as possible. This may, however, not be the most important issue as data rates from radiometers are comparatively modest due to generally coarse ground resolution compared with other sensors. The radiometer integration time is, however, closely related with the necessary sampling time(in the radiometers discussed in the present paper the sampling time and the integration time are equal). Hence finding the maximum sampling time is also finding the maximum integration time and thereby an important parameter in the acheivable radiometric sensitivity

\section{References}

Gloersen, P., Barath, F.T. (1977):

"A Scanning Multi-channel Microwave Radiometer for NIMBUS-G and

SEASAT-A IEEE OE-2, April

Hollinger, J.P., Lo, R.C. (1984):

"Low-Frequency Microwave Radiometers for N-Ross". Large Space Antenna Systems Technology, NASA Conf, Publication 2368

"The NIMBUS-7 Users` Guide" (1978) NASA Goddard Space Flight Center, Greenbelt, Maryland 